\title{
Welfare technology and user experience: a study of seniors' expectations on and first impressions of a robotic shower
}

\author{
Charlotte Bäccman \\ CTF - Service Research Center \\ Karlstad University, Sweden \\ charlotte.baccman@kau.se
}

\author{
Linda Bergkvist \\ CTF - Service Research Center \\ Karlstad University, Sweden \\ linda.bergkvist@kau.se
}

\begin{abstract}
This study shows that seniors strive to become more independent and that acceptance of welfare technology needs to be understood in the specific situation. User experiences from welfare technology, such as the robotic shower, that serve in a very intimate situation, may not be comparable to the results from previous studies of, for example, surveillance technology.

The preliminary results in this paper build on both qualitative and quantitative data, and show that seniors are in general positive to replacing the current shower situation with a more autonomous shower situation as provided by the robotic shower. An important aspect for acceptance was the functionality of the robotic shower. Furthermore, this study showed that the understanding of the shower situation in general can be used for improvement of the current shower situation, to prevent learned helplessness.
\end{abstract}

\section{Introduction}

Globally, we are looking at an increasingly skewed distribution of population in terms of age: with an increase of older people and a decrease of people able to work and pay for the welfare of both the elderly and the young [1]. At the same time the healthcare cost increases with age, the healthcare cost for an 85-year-old is almost 10 times higher than for a 75-year-old, and this cost increases exponentially from there on, according to a report from the Swedish Treasury [2]. Thus, there is an urgent need to find solutions that may help come to terms with the challenges this brings ahead. In particular research on services that improve healthcare and well-being has been called for [3]. One way of dealing with some of the challenges is digitalization and welfare technology [4].

Welfare technology can be described as technical or digital services and products that aim to facilitate everyday tasks for seniors, chronically ill and disabled persons [5]. Furthermore, welfare technology should be useful both for the user and personnel or people in the user's vicinity. Welfare technology may range from e-services to digital safety alarms, camera supervision at night, and medicine reminders, to name a few of the most commonly used welfare technology services in Sweden [6]. Another type of welfare technology are service robots, and some researchers estimate that $90 \%$ of future services will be operated by service robots in 2030 [7]. Still, little is known about how to incorporate welfare technology in everyday life and work processes to optimize its benefits [8]. User experiences, user acceptance and adoption of welfare technology are areas still to be explored [8-10]. The mere presence of technological solutions will not increase effectiveness. Indeed several studies imply that there is organizational resistance to the implementation of new technology, similar to that of organizational changes in general $[11,12]$. The ongoing development of welfare technology on the one hand and, the foreseeable growth of seniors with healthcare needs on the other hand, raises the question of what contribution welfare technology can have when it comes to rationalizing, maintaining, or perhaps even improving, the quality of healthcare [1]. Thus, it is imperative to study the effectiveness of welfare technology, both to ensure its usefulness, and quality.

Some of the healthcare situations paved with challenges for the clients are those related to personal hygiene. Failing to take care of one's own basic needs such as going to the bathroom, or having a shower, due either to an aging body or a disability, temporary or permanent, will probably evoke feelings of embarrassment, distress and frustration. Yet, it may not only be the clients' feelings that will hurt. Research shows that dependence feeds dependence, that is, dependence tends to spread from one area to another, so-called learned helplessness [13-17]. Indeed, providing the opportunity for the clients to feel empowered to take responsibility for their own life is important both for 
their well-being and future needs for other healthcare services. One way of meeting the clients' need for continued (or restored) integrity and independence can be to provide welfare technology that can help in these hygiene situations. For example, a combined toilet and bidet, a so-called Washlet, enables the clients to go to the bathroom without assistance. These toilet solutions are quite common and can be found at several retailers. Taken together, welfare technology within the healthcare sector have the potential to increase effectiveness and enhance clients' independence, however a deeper understanding for how users accept and adopt new welfare technological solutions is needed.

In regard to this, an investigation with a clear user perspective of the shower situation, and the possibility for improvements by means of the robotic shower, was designed. Hence, note that this study was not designed to improve the robotic shower. The robotic shower, called Poseidon, is a new Swedish invention by Robotics Care [18] and aims to empower seniors' and disabled persons' independence and autonomy in the shower situation. Additionally, the robotic shower aims to reduce the physical strain put on the personnel during the shower situations, who now are at risk for slipping and hurting themselves while showering a client.

The aim of this paper was twofold: (a) an initial exploration of if and how seniors' current shower situation can be improved by means of the robotic shower; and (b) to learn more about the seniors' first impressions and initial experiences of the robotic shower.

\section{Theoretical background}

\subsection{User perspectives and welfare technology in healthcare}

Users' perception of usability and ease-of-use are known as the technology acceptance model (TAM) $[19,20]$, and considered key aspects for the acceptance and adoption of new technology [10]. Perceived usability regards how the technical solution is considered to improve or alleviate a task. Perceived ease-of-use is the user's perception of how easy to use the technological solution is. Studies have shown that successful implementation of new technology is preceded by letting the users be part of the innovation design, so that the technology is adapted for the users and not the other way around $[5,21,22]$. Furthermore, technology acceptance and adoption is further strengthen if the process is made in the environment in which the users are operating [5]. Thus, it is important to foster a situation where the technical solutions are developed and adapted for the actual users, service and situation for which they are intended.

In addition to this user centric design, researchers have learnt that users' self-efficacy will influence their acceptance and adoption [23, 24]. Self-efficacy regards a person's belief in and perception of his/her own ability to deal with emerging problems and stressors [25], here, it regards a person's belief that he/she can handle and learn technology. Some studies label this ability as computer self-efficacy [26], technical self-efficacy (TSE) [10], or as technical readiness [27]. The latter is more focused on actual experience and attitudes towards new technology. Studies have shown that healthcare personnel with higher TSE tends to be more positive toward technical solutions and, thus more accepting than those with lower TSE [10]. Similarly, Gücin and Berk [28] found that seniors with higher TSE were more prone to increase their use of computers.

All in all, there seem to be both situational and individual variations that will influence the acceptance and adoption of new technology.

\subsection{Previous studies with a user perspective on welfare technology in healthcare}

Studies so far seem to imply that welfare technology can increase a client's independence and freedom, from mobility to everyday tasks, such as eating or bathroom visits $[16,29]$. Increased independence and freedom will in turn lead to a decreased burden for the non-professional care takers (e.g., spouse) who no longer will be needed for these tasks. Thus, welfare technology enables family and/or friends to maintain their primary social role to the client [30]. Welfare technology is therefore not only valuable to the client but also to his/her close family and friends.

The client's and his/her family's well-being increases if they are involved in the decision if and how the welfare technology is to be used [29]. User involvement is also necessary for the clients and their families to trust welfare technology, such as different alarms and surveillance devices [16, 31, 32]. When everything works it may help improved quality of life $[34,35]$. When the technology feels alien or fails to work properly it evokes negative feelings of discomforted and apprehension and may increase stress, as well as uncertainty about if and when the product is to be used $[33,36]$. Thus, despite some limitations the usefulness of welfare technology seems to be overall positive.

Still, there are more aspects to consider in regard to the user perspective when it comes to welfare technology. One important aspect regards the social interaction that may be lost when people are replaced with 
welfare technological solutions. Both clients and personnel may fear that welfare technology will result in diminished human interactions, and when some clients are given the choice of a task being handled by a technical solution or a person, they choose the person [31, 32]. To some clients, it seems as if the social interaction is more valuable than independence and integrity and to them technology is therefore not a desirable solution.

Social isolation is a well-known risk factor for several health issues such as increased risk of mortality, increased risk for infections, and deceased well-being $[37,38]$. In Sweden more than a third of all seniors live alone [39], and loneliness applies to both seniors in assisted living facilities and at home, who receive home care assistance [40]. According to a survey of the Swedish National Board of Health and Care [6] 30\% of all men and women who are 80 years old or older, request assistance for participation in social activities. In general, women seem to be more vulnerable to social isolation than men as they have a longer life-expectancy. Indeed, $50 \%$ of all women over 78 -years of age live by themselves [8].

Taken together, there are several aspects to consider in understanding users' acceptance and adoption of welfare technology. If the purpose of the welfare technology is to improve quality of life, it is of utmost importance that the actual users are allowed to participate and evaluate the welfare technological solution in the specific service situation $[5,41]$.

\section{Method}

\subsection{Design and procedure}

This paper is part of a longitudinal, explorative research study which focuses on the user experiences of the robotic shower from a dual perspective, that is both personnel's and seniors' experiences. The setting of the study is an assisted living facility in a Swedish, medium-sized municipality.

The longitudinal design aims to assess participants' expectations on and experiences from the robotic shower before, during, and after. The assessments at three different times makes it possible to evaluate if user experiences change over time [42].

Both quantitative and qualitative data are gathered. The qualitative data was collected before the robotic shower had been used (T1, Jan-Feb 2018) and after circa 2-3 months after the robotic shower was put in use (T2, April-May, 2018). The purpose of the qualitative data was to explore how the participants experienced their current shower situation and their initial expectations on the robotic shower.
The quantitative data was collected by means of a short questionnaire. The participants were asked to fill in the questionnaire every time they had used the robotic shower. The intention of the questionnaire was threefold: firstly, we wanted to see if there were differences regarding user experiences related to their perception of their own technical confidence. Secondly, we wanted to see how the participants perceived the characteristics of the robotic shower and its functions; and, thirdly, if the perception changed as a function of how many times they have used the shower.

Note that this paper builds on data solely from seniors who participated at the first interview and seniors' questionnaires.

The project has been approved by the Ethical Vetting Board in Uppsala (Date of approval: 08-11-2017; registration no. 2017/442).

\subsection{The robotic shower}

The robotic shower, Poseidon, is still a prototype in only five editions, and has been invented, developed and provided by a Swedish company, Robotics Care [18]. The robotic shower is equipped with an automatic chair that extends on a mechanical arm to pick up and drop off a person outside the shower. The shower cabin's sides are frosted for privacy. The user starts the program, which can be set and customized individually (e.g. water heat and pressure), with a simple push on a button. Soap and water are distributed using a total of 14 shower heads adapted to access the upper and lower body, as well as backside and genitals. The functionality also includes hand shower and emergency alarm.

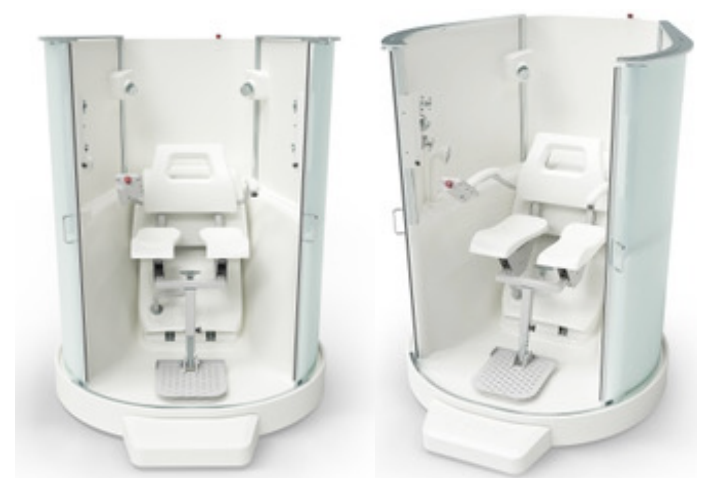

Figure 1. The robotic shower. 


\subsection{Participants}

The participants were selected based on convenience by representatives from the municipality. All participants were clients at the assisted living facility, who stayed there either full or part time. The participants' reasons for staying at the assisted living facility varied with disabilities including partial paralysis, dementia, and limited mobility, thus varying from cognitive to physical. All of the participants showered with support from home care service personnel or the facility personnel. The degree of required support varied from client to client. While some required help during the entire shower situation, that is help with being undressed, showered, dried and dressed, others managed parts of the shower situation by themselves.

Inclusion criteria for the qualitative study were: (a) that the clients normally needed help in the shower situation, (b) were healthy enough that they might gain from a robotic shower, and (c) were willing and able to be interviewed, as all participants were required to sign a consent form before the interview. In this paper the sample for the qualitative analysis consisted of five seniors, between 71 to 82 years of age, and one middle aged (58 years) $(n=6)$.

The inclusion criterion for the quantitative study was anyone who had the opportunity to use the robotic shower; and this sample will therefore overlap with the qualitative sample. The sample consisted of 16 men and 7 women $(n=23)$ between the ages 58 to 95 (mean $=81$ ). With the exception from one participant who had used the robotic shower twice, all other participants had only used the robotic shower once.

There were no significant differences ( $n s$.$) be-$ tween men and women regarding age or the dependent variables (described below in the Data collection section).

\subsection{Data collection}

The interviews were semi-structured with focus on the participants' experiences from their current shower situation at home or at the assisted living facility. The participants were encouraged to bring up both positive and negative experiences and aspects of the current shower situation, as well as expectations (if any) on the robotic shower.

The quantitative data, that is the questionnaire, comprised of four parts. The first part regarded background information, such as, age, sex, type of disability and how they usually shower at home or at the assisted living facility.
The second part regarded the participants technical confidence, where one question regarded the participants' Technical savvy (e.g., "I'm used to modern technical solutions in my everyday life, such as safety alarms, computers, internet, mobile phones"), and 5 items made up a scale of the participants' Technical self-efficacy (TSE; e.g., "I'm comfortable with trying different technical solutions"). All 5 items were adapted to be technologically general, the first two items from the Swedish adapted version of Bandura's self-efficacy scale [43] and the following three items from Compeau and Higgin's computer self-efficacy [26]. By this second part we wanted to investigate how technical savviness correlated to TSE and acceptance of the robotic shower. All items were answered on a 10 -graded scale ranging from "Total disagreement" to "Total agreement". The same 10-graded scale was used throughout the questionnaire.

The third part was made up by 13 items referring to TAM [19] and was adapted by means of wording for the shower. The first 6 items regarded the robotic shower's Usability (e.g., "The robotic shower made it easy and comfortable for me to have a shower"). The following 5 items regarded the robotic shower's availability, Ease-of-use (e.g., "I found the robotic shower easy to use"); and the last 2 items regarded $A c$ ceptance, that is, if the participants wanted to use the robotic shower again and/or if they would prefer to use the robotic shower to the ordinary shower.

The fourth part comprised of 9 items asking specifically about the robotic shower's technical Functionality. Thus, these items ranged from safety to water temperature and pressure. Examples of items in this scale are: "The robotic shower felt safe", and "The chair in the shower was comfortable to sit on". At the end of the questionnaire participants could write down comments and reflections.

\subsection{Data analysis}

The qualitative analysis was made according to thematic analysis where the semantic/explicit meaning of the interview was analyzed [44]. The analysis model proposes six different steps where the first step is to get to know the data. The second step is coding the different meaning bearing units, here a meaning bearing unit can range from one to several sentences, representing communalities among the units within the code. The coding in this step is still kept close to the actual data content.

The third step is to find so called protothemes, which requires an interpretation of the initial coding. Here, the codes were combined or split according to common themes. This third step also requires the re- 
searcher to go back into the codes and check for inconsistencies. In the fourth step, the themes were reviewed and reanalyzed according to the emergent protothemes. The fifth step is generally a refinement of the themes as well as giving them distinctive and representative labels. At this point a preliminary understanding of the data emerged from the themes. The last step according to Braun and Clark [44] is to report the data in writing. A summary of the themes, protothemes and examples of codes is presented in Table 1 .

The quantitative analysis was made in SPSS 25.0. Due to the small sample and non-normally distributed data all analyses were non-parametric.

\section{Table 1. Summary of themes, protothemes} and codes.

\begin{tabular}{lll}
\hline Themes & Protothemes & Codes \\
\hline $\begin{array}{l}\text { Independ- } \\
\text { ence }\end{array}$ & Outcome & $\begin{array}{l}\text { Feeling of being fresh, not } \\
\text { thoroughly showered, degree } \\
\text { of clean hair, clean face }\end{array}$ \\
\hline & Control & $\begin{array}{l}\text { Influence over the shower situ- } \\
\text { ation, decide who showers, de- } \\
\text { cide when to shower and how } \\
\text { long, can wash themselves }\end{array}$ \\
\hline & Gratitude & $\begin{array}{l}\text { Don't want to make demands, } \\
\text { gratefulness, resignation, in- } \\
\text { debtedness }\end{array}$ \\
& Partial & $\begin{array}{l}\text { Still need assistance during } \\
\text { some part of the shower situa- } \\
\text { tion }\end{array}$ \\
\hline dependence & $\begin{array}{l}\text { Expectant, curious, exciting, } \\
\text { optimism }\end{array}$ \\
\hline $\begin{array}{l}\text { Contextual } \\
\text { issues }\end{array}$ & Detachment & $\begin{array}{l}\text { Impersonal, time constraints, a } \\
\text { chore }\end{array}$ \\
\hline & Practical \\
concerns & $\begin{array}{l}\text { Available help, hearsay, wor- } \\
\text { ries concerning the functional- } \\
\text { ity of the robotic shower, pri- } \\
\text { vacy, accessibility }\end{array}$ \\
& &
\end{tabular}

\section{Results}

\subsection{Results from the qualitative analysis}

In the tentative analysis two themes, Independence and Contextual issues, emerged. These themes were made up by seven protothemes and serve to understand the clients' experiences from their current shower situation and how the shower situation can be improved, for example by means of a robotic shower.

\subsubsection{Independence}

Five protothemes were identified representing the theme Independence: Outcome, Control, Gratitude, Partial dependence, and Hopefulness. Overall this theme represents the participants' strive for independence and can be derived both from statements regarding the current shower situation and their expectations on the robotic shower.

In the first prototheme, Outcome, the participants expressed both positive and negative experiences regarding the effectiveness of the current shower situation, for example how clean they felt. However, to what degree the participants felt clean seemed to vary with whom was assisting the shower situation.

The second prototheme, Control, regarded the participants' experience of having influence, or rather lack of influence, over the shower situation. For example, not having a say in when to shower, for how long, or by whom. The latter can be about the gender of the assisting person where some of the participants felt more comfortable with being showered by same-sex personnel, whereas others did not care. The participants experience of lack of control can be illustrated in the following two quotations:

\section{Sometimes [...] I would like them to help me to move from the wheelchair to the shower chair, then I would manage by myself. They [personnel] do not have time for that.}

I get help moving from the wheelchair to the shower. Then I can soap myself but the [personnel] go somewhere else, close the door, and that is unsafe. [Personnel] should stay in the shower room.

Gratitude is the third prototheme that illustrates the dependence of the participants. The participants were reluctant to express displeasure with the personnel or the service provided in a direct manner. Many of the participants were thankful for the possibility of being showered at all. One participant expressed it as:

[I]t is very different how [the personnel] do the hair wash. But it is, it is not negative, but [...], [the personnel] do the best they can.

Our interpretation is that the participants felt too reliant on the personnel to feel comfortable asking for additional or improved services. It could also be an expression for sympathizing with the personnel's current work situation.

The fourth prototheme, Partial independence, concerns the participants' awareness that there are some limitations to what degree of independence the robotic shower can contribute to. Some clients expressed that they still will need assistance, for undressing and dressing, or for transference from wheelchair to the ro- 
botic shower. Yet, the majority of the participants expected to shower by themselves, thus having independence during the actual shower.

The fifth and last prototheme, Hopefulness, represents the participants' overall positive emotions towards a more independent shower situation, expected to be enabled by the robotic shower, as expressed in: "[trying the robotic shower] will be exciting" and "[the robotic shower] seems terrific". One of the participants expressed her expectations of being independent:

I won't need to ask for help. Some days I don't want to shower in the morning but after breakfast. And then I can do that, I will not be dependent on someone else [...]. To decide by myself, it would be great.

Thus, the theme Independence was made up by a variety of statements, in both negative and positive terms, regarding the participants' experience of the current shower situation as well as their expectations on the robotic shower.

\subsubsection{Contextual issues}

The second theme was made up by two protothemes: Detachment and Practical concerns.

The first prototheme, Detachment, is based on the participants' description of the shower routine as mechanical, rather than based on the client's needs and wishes. This experience is highlighted by one of the participants who describe it as: "[the personnel] are just scrubbing me off". In addition, the shower situation is described as rushed and time constrained, as illustrated in " ..../ I get clean but [the personnel] is very rushed. Well sometimes I would like to sit there longer, but, there is no time".

The second prototheme, Practical concerns, regards the functionality of the robotic shower and its localization at the facility. For example, one participant worried about specific functionalities: "when you push on soap, the soap will not come in my eyes?", whereas others were more concerned about safety, as expressed in: "is it easy to push the buttons? I mean so you don't push on something and then you get locked up", and "someone is with you, someone who can monitor the shower situation?". These participants had only heard about the robotic shower from other clients at the living facility, hence their concerns were triggered by rumors and hearsay. Another participant reflected on the location of the robotic shower at the assisted living facility and wondered who would be authorized to be in the room.
Thus, this theme seems to convey more contextual issues that lie in the organization, such as information flow and transparency, time management and actual placement of the robotic shower on the facility.

\subsection{Results from the quantitative analysis}

The descriptive statistics for the quantitative data are presented in Table 2. The participants' overall TSE and first-time experience of the robotic shower in terms of both TAM and Functionality was mainly positive, with averages ranging from 6.03 to 6.81 . The item regarding Technical savvy was somewhat lower, but still what should be considered an average level (5.45). Table 2 also shows that, although the participants' acceptance of the robotic shower was positive, there was a large range within the group. A closer look revealed that 5 of the participants did not want to use the robotic shower again and/or preferred their ordinary shower routine; and 7 of the participants were of the opposite opinion and preferred the robotic shower and wanted to use it again.

Table 2. Descriptive statistics for the dependent variables.

\begin{tabular}{l|cccc}
\hline Variables & $\boldsymbol{N}$ & Mean $(S \boldsymbol{D})$ & Range & $\begin{array}{c}\text { Scale } \\
\text { relibility }\end{array}$ \\
\hline Tech savvy & 23 & $5.48(2.79)$ & $1.00-10.00$ & -- \\
TSE & 23 & $6.51(2.43)$ & $1.40-10.00$ & $\alpha=.94$ \\
Usability & 22 & $6.40(2.34)$ & $2.00-10.00$ & $\alpha=.90$ \\
Ease-of-use & 22 & $6.03(2.64)$ & $1.00-9.60$ & $\alpha=.88$ \\
Acceptance & 22 & $6.05(3.44)$ & $1.00-10.00$ & $r=.75^{*}$ \\
Functionality & 23 & $6.81(1.83)$ & $1.78-9.41$ & $\alpha=.82$ \\
\hline
\end{tabular}

Note. Usability, Ease-of-use, and Acceptance = TAM

*Acceptance scale a proxy by Spearman's rho of its two items.

A correlation analysis (Spearman's rho) revealed that there is a positive and medium strong significant $(r=.44 ; p<.05)$ correlation between participants' level of Tech savvy and their TSE (Table 3). In other words, participants who saw themselves as used to different technological solutions were also more confident of their overall ability to learn and use new technical devices.

Furthermore, participants with higher TSE found it easier to use the robotic shower than participants with lower TSE. Ease-of-use was also strongly connected to Usability. Thus, it seems as participants who found the robotic shower easy to use, also saw its possibilities to facilitate the shower situation. 
Table 3. Correlations (Spearman's rho) between the dependent variables.

\begin{tabular}{l|cccccc}
\hline \multicolumn{1}{l|}{} & 1. & 2. & 3. & 4. & 5. & 6. \\
\hline 1. Tech savvy & -- & & & & & \\
2. TSE & $\mathbf{. 4 4}$ & -- & & & & \\
3. Usability & .01 & .23 & -- & & & \\
4. Ease-of-use & .29 & $\mathbf{. 6 1}$ & $\mathbf{. 6 2}$ & -- & & \\
5. Acceptance & .26 & .24 & .32 & .40 & -- & \\
6. Functionality & .01 & .36 & .20 & .24 & $\mathbf{. 5 2}$ & -- \\
\hline
\end{tabular}

Note. Usability, Easy to use, and Acceptance = TAM.

Significant correlations ( $p<.05$, two tailed) in bold.

Whether the participants accepted the robotic shower, that is were more willing to use it again and/or wanted it to replace their ordinary shower, was solely and strongly connected to how they rated its Functionality.

\section{Discussion}

The overall result from the qualitative analysis seems to imply that the current shower situation can be improved by means of the robotic shower. The analysis revealed that the participants wished for a more independent shower situation, for example being able to shower when and for as long as they would like, as well as feeling thoroughly showered. Most participants expressed aspects of the current shower situation that could be improved, however few seemed to have been able to influence their shower situation. The reasons for this varied, some had not been heard, another had not been able to express this to the caregivers, and yet another did not feel that their opinions were rightful. The participants desire for increased independence was also mirrored as positive expectations on the robotic shower. However, they were still aware of that they might not become entirely independent in the shower situation due to different physical impairments, where some still needed help to get undressed and so on. In addition, the participants expressed discontentment due to how the actual shower routine was performed. The act itself was seen as mechanical and impersonal and time constraints were often highlighted.

The fact that the participants felt like the personnel took over the shower situation, may foster dependence and learned helplessness [13-17]. In the short run this mechanical way of giving a shower may seem effective from a time perspective. However, in the long run this way of conducting the shower situation may lead to increasingly dependent clients, not only in the shower situation, but also for other healthcare services [13].
We were somewhat surprised that even the participants who in many ways are considered to be very care-dependent still were able to voice their discontentment as well as by their innate wish to remain independent. Whether their acceptance of a dissatisfactory shower situation is a characteristic of learned helplessness or a sign that the participants have not fully reached this state is at this point impossible to say. Thus, we need a deeper understanding for how learned helplessness in care situations works, if it for example exists a point-of-no-return or if it can always be reversed.

The result from the qualitative analysis shows the importance of user involvement for the experienced value of a service, whether it includes technology or not [cf. 5, 19,41]. As it seems, it is not only technology but also contextual issues, such as routines and time constraints, that can alienate and create feelings of discomforted and apprehension if the clients are not involved [33, 45].

The participants in this study did not explicitly express a need for or loss of social interaction if the robotic shower would replace the current shower routine. This is in contrast to previous studies [cf. 31,32] where clients chose to be aided by a person instead of technical solutions; as well as the study of Kristensson and colleagues [32] which showed that people in general are suspicious when it comes to new technology. One explanation may be that the shower situation itself, that is being naked and washed, is such an intimate situation (together with perhaps, bathroom visits and eating), that other types of situations not are comparable. Since most studies on welfare technology and user experiences have been made on safety alarms and surveillance devices $[16,31,32,34,35]$, more studies are needed to fully understand user acceptance of welfare technology designed for more intimate situations and services. Based on this, this study suggests that user acceptance of welfare technology may need to be understood in regard to the specific service situation (i.e., how intimate the situation may be), and not only in terms of user involvement [e.g. 5] or technological readiness [27].

Despite the overall positive expectations on the robotic shower, there were also concerns, triggered mainly by lack of information and hearsay. Normally the participants were showered in their en suit bathroom, but since there was only one robotic shower it was placed in an area where all the clients could have access to it. Thus, this meant that most participants had not seen the robotic shower, or had been to that part of the facility at the time for the interview. Thus, in line with previous research [33], this result accentuates the 
importance of rich information to avoid false representations and feelings of uncertainty as well as to facilitate implementation of welfare technology.

The result from the quantitative analysis revealed that the first impression of the robotic shower was overall positive. However, there was a wide range where some participants were very positive and others were very negative. As expected the participants' technical experience was closely connected to TSE $[10,25$, 26]. In addition, TSE was positively connected to how easy to use they found the robotic shower. In contrast to previous studies [23, 24], TSE was not related to usability or acceptance of the shower.

User acceptance in terms of wanting to use the robotic shower again and/or replacing the current shower routine was only related to the actual functionality of the robotic shower (i.e., water pressure, soap, and/or safety and comfort). In addition, participants who found the robotic shower easy to use were also more inclined to find it usable, that is recognized its possibilities to facilitate the shower routine. Thus, from user acceptance point of view it is important that welfare technology is both easy to use and provide satisfactory functionality [ $c f .46]$.

It should be noted that Ease-of-use, Usability and Acceptance, according to TAM [19] normally refers to information technology, why the theory may not be fully applicable on welfare technology. This highlights the need for further studies on user acceptance of welfare technology, and the importance to include aspects of functionality.

\section{Limitations}

As this paper relies on partial and preliminary data from a larger research study it is paved with some limitations. One limitation is the small sample size, which is due to that this paper is part of an ongoing research study where all data is yet to be collected. In the full research study, the sample includes personnel, and all in all there will be circa 20 interviews from T1 and T2, as well as personnel questionnaires.

Another limitation is that the questionnaire items Tech savvy and TSE have been adapted for this study, and thus, not properly validated as of yet [cf. 47]. Having said this, the scales show high internal consistency and variance which implies a suitable item difficulty [48]. Naturally, further validation is called for both in terms of item analysis and cross-validations [48].

Another, possible, limitation is that the study only regards a Swedish context. Still, most studies are conducted in a specific context, be it cultural or other, and contribute to the overall knowledge accumulation of user experience and user acceptance.

\section{Conclusions}

Seniors strive to become more independent in the shower situation and welfare technological solutions, such as the robotic shower, may empower this independence. The understanding for how seniors experiences their current shower situation enables improvements that empower seniors' independence, with or without the robotic shower. Taking away the seniors' control and involvement in their own shower situation, put them at risk for learned helplessness.

Another conclusion is that acceptance of welfare technology may look different from one service situation to another, and that the functionality of the solution seem to be of greater importance. Thus, existing theories regarding for example user acceptance and adoption of technology may not fully apply to welfare technology.

\section{Acknowledgement}

The authors would like to thank the Health and Care Administration at the municipality for co-funding this study, and the personnel and clients at the assisted living facility for their cooperation and participation.

\section{References}

[1] J. F. Coughlin, J. E. Pope, R. Ben, and J. Leedle, "Old age, new technology, and future innovations in disease management and home health care.," Home Health Care Management \& Practice, vol. 18, no. 3, 2006, pp. 196-207.

[2] The Swedish Treasury. (2015). SOU 2015:101, Demografins regionala utmaningar (in Swedish). Available: http://www.regeringen.se/4ae771/contentassets/15c00134b $\underline{\text { 8b4439185d351b14765da2a/demografins-regionala- }}$ utmaningar-sou-2015101

[3] A. L. Ostrom, M. J. Bitner, S. W. Brown, K. A. Burkhard, M. Goul, V. Smith-Daniels, H. Demirkan, and E. Rabinovich, "Moving forward and making a di erence: Research priorities for the science of service.," Journal of Service Research, vol. 13, no. 1, 2010, pp. 4-36.

[4] O. T. Mytton, A. Velazquez, R. Banken, J. L. Mathew, T. S. Ikonen, K. Taylor, F. Painter, R. Jean-Baptiste, A. Poon, and E. Ruelas, "Introducing new technology safely," BMJ Quality \& Safety, vol. 19, no. 2, 2010, pp. i9-i14.

[5] A. D. Öberg and B. Rolfer, "Välfärdsteknologi handlar inte om teknik utan om människor - tekniksprång i nordisk demensvård. Nordens välfärdscenter. (in Swedish)," 2017, Available: http://nordicwelfare.org/PageFiles/41831/Demens- 
inspirationsha\%cc\%88fte-webb.pdf. Accessed on: 20170830.

[6] The Swedish National Board of Health and Care. (2017). Välfärdsteknik (in Swedish). Available: http://termbank.socialstyrelsen.se/?TermId=798\&SrcLang= $\underline{\text { SV }}$

[7] C. B. Frey and M. Osborne, "The future of employment," 2013, Available: https://pdfs.semanticscholar.org/0822/f0b701e0b798c670d 23c3e85b5f4ec31bd22.pdf, Accessed on: 07062018.

[8] Ministry of Health and Social Affairs. (2017). SOU 2017:21 Part 2., Nationell kvalitetsplan för vård och omsorg om äldre personer (in Swedish). Available: http://www.regeringen.se/4969b7/contentassets/9378aff4b3 5a427c99b772345af79539/sou-

2017 21 webb del2 hela.pdf.

[9] P. Y. K. Chau and P. J.-H. Hu, "Investigating healthcare professionals' decisions to accept telemedicine technology: An empirical test of competing theories," Information \& Management, vol. 39, no. 4, 2002, pp. 297-311.

[10] M. J. Rho, I. Y. Choir, and J. Lee, "Predictive factors of telemedicine service acceptance and behavioral intention of physicians," International Journal of Medical Informatics, vol. 83, no. 8, 2014, pp. 559-571.

[11] M. J. Martinko, R. W. Zmud, and J. W. Henry, "An attributional explanation of individual resistance to the introduction of information technologies in the workplace.," Behaviour \& Information Technology, vol. 15, no. 5, 1996, pp. 313-330.

[12] B. Karsh, "Beyond usability: designing effective technology implementation systems to promote patient safety," BMJ Quality \& Safety, vol. 13, 2004, pp. 388-394.

[13] M. Faulkner, "The onset and alleviation of learned helplessness in older hospitalized people," Aging \& Mental Health, vol. 5, no. 4, 2001, pp. 379-386.

[14] R. B. Flannery, Jr. , "Treating learned helplessness in the elderly dementia patient: Preliminary inquiry," American Journal Of Alzheimer's Disease And Other Dementias, vol. 17 , no. 6 , 2002, pp. 345-349.

[15] D. Hiroto and M. E. P. Seligman, "Generality of learned helplessness in man," Journal of Personality and Social Psychology, vol. 31, no. 2, 1975, pp. 311-327.

[16] A. R. Niemeijer, B. J. M. Frederiks, I. I. Riphagen, J. Legemaate, J. A. Eefsting, and M. P. M. Hertogh, "Ethical and practical concerns of surveillance technologies in residential care for people with dementia or intellectual disabilities: An overview of the literature," International Psychogeriatrics, vol. 22, no. 7, 2010, pp. 1129-1142.
[17] M. E. P. Seligman, Learned optimism. How to change your mind and your life. Riverside, US: Simon \& Schuster, 2011.

[18] RoboticsCare. (2017, 07062018). Poseidon - den intelligenta duschlösningen (in Swedish). Available: http://www.roboticscare.com/poseidon/

[19] F. D. Davis, "Perceived usefulness, perceived ease of use, and user acceptance of information technology," MIS Quarterly, vol. 13, no. 3, 1989, pp.319-340.

[20] V. Venkatesh and F. D. Davis, "A theoretical extension of the technology acceptance model: Four longitudinal field studies," Management Science, vol. 46, no. 2, 2000, pp. 186204.

[21] ISO9241-11. (11062018). ISO 9241-11, Standards dealing with the product development process. Available: http://www.usabilitypartners.se/about-usability/isostandards.php

[22] ISO9241-210. (110618). ISO 9241-210, Standards in usability and user-centred design. Available: http://www.usabilitypartners.se/about-usability/isostandards.php

[23] S-Y. Hung, Y-C. Ku, and J-C. Chien, "Understanding physicians' acceptance of the medline system for practicing evidence-based medicine: A decomposed tpb model.," International Journal of Medical Informatics, vol. 8, no. 12, 2012, pp. 130-142.

[24] C. D. Melas, L. A. Zampetakis, A. Dimopoulou, and V. Moustakis, "Modeling the acceptance of clinical information systems among hospital medical staff: An extended tam model," Journal of Biomedical Informatics, vol. 44, no. 4, 2011, pp. 553-564.

[25] A. Bandura, "Self-efficacy: toward a unifying theory of behavioral change.," Psychological review, vol. 84, no. 2, 1977, pp. 191-215.

[26] D. R. Compeau and C. A. Higgins, "Computer selfefficacy: Development of a measure and initial test," MIS Quarterly, vol. 19, no. 2, 1995, pp. 189-211.

[27] A. Parasuraman and C. L. Colby, "An updated and streamlined technology readiness index: TRI 2.0," Journal of Service Research, vol. 18, no. 1, 2015, pp. 59-74.

[28] N. Ö. Gücin and Ö. S. Berk, "Technology acceptance in health care: An integrative review of predictive factors and intervention programs," Procedia - Social and Behavioral Sciences, vol. 195, 2015, pp. 1698-1704.

[29] A. Melander-Wikman, Y. Fältholm, and G. Gard, "Safety vs. privacy: elderly persons' experiences of a mobile 
safety alarm," Health and Social care in the community, vol. 16 , no. 4, 2008, pp. 337-346.

[30] E. B. White and P. Montgomery, "Electronic tracking for people with dementia: An exploratory study of the ethical issues experienced by carers in making decisions about usage," Dementia, vol. 13, no. 2, 2014, pp. 216-232.

[31] J. F. Coughlin, "Understanding the janus face of technology and ageing: Implications for older consumers, business innovation and society.," International Journal of Emerging Technologies and Society, vol. 8, no. 2, 2010, pp. 62-67.

[32] A. M. Dorsten, S. K. Sifford, B. A., P. M. L., and H. Wactlar, "Ethical perspectives on emerging assistive technologies: Insights from focus groups with stakeholders in long-term care facilities," Journal of Empirical Research on Human Research Ethics, vol. 4, no. 1, 2009, pp. 25-36.

[33] A. Olsson, M. Engström, K. Skovdahl, and C. Lampic, "My, your and our needs for safety and security: Relatives' reflections on using information and communication technology in dementia care," Scandinavian Journal of Caring sciences, vol. 26, 2011, pp. 104-112.

[34] C. Abrahamson-Löfström and N. Larsson, "Nattfrid? Om tillsyn på natten för äldre personer med hemtjänst (in Swedish)," Hjälpmedelsinstitutet, Sundbyberg,2012.

[35] Nestor, "Innocare - test av teknikprodukter i Nacka kommun (in Swedish)," 2014, Available: http://infobank.nacka.se/handlingar/social och aldrenamnd en/2014/2014-05-

20/06 2 Teknikstod i hemmet Bilaga 1.pdf. , Accessed on: 01062018 .

[36] N-O. Ørjasæter and K. Misvær, "Velferdsteknologi i Sentrum. Införing av velferdsteknologi i sentrumsbydelene i Oslo. En kartleggning av effekten (in Norwegian)," 2015 , Available: https://helsedirektoratet.no/Documents/Velferdsteknologi/ Velferdsteksnologi\%20i\%20sentrum delleveranse $\% 201 \% 2$ 0av\%202.pdf, Accessed on: 07062018.

[37] A. P. Dickens, S. H. Richards, C. J. Greaves, and J. L. Campbell, "Interventions targeting social isolation in older people: A systematic review," BMC public health, vol. 11, no. 1, 2011, pp. 647-669.

[38] F. Landeiro, P. Barrows, E. N. Musson, A. M. Gray, and J. Leal, "Reducing social isolation and loneliness in older people: A systematic review protocol," BMJ open, vol. 7, no. 5, 2017, p. e013778.

[39] The Swedish Agency for Health and Care Analysis. (2015). 2015:8, Hemtjänst, vård-och omsorgsboende eller mitt emellan? (in Swedish). Available: https://www.vardanalys.se/rapporter/hemtjanst-vard-ochomsorgsboende-eller-mitt-emellan/

[40] SKL, "Rena fakta om välfärden. Vi vässar välfärden (in Swedish)," Swedish Association of Local Authorities and Regions,03062018, 2017, Available: http://webbutik.skl.se/bilder/artiklar/pdf/7585-4069.pdf?issuusl=ignore.

[41] P. Kristensson, A. Brunstrom, and T. Pedersen, "Affective forecasting of value creation: Professional nurses' ability to predict and remember the experienced value of a telemedicine diagnostics ICT service," Behaviour \& Information Technology, vol. 34, no. 10, 2015, pp. 964-975.

[42] P. Y. K. Chau, "An empirical assessment of a modified technology acceptance model," Journal of Management Information Systems, vol. 13, no. 2, 1996, pp. 185-204.

[43] J. Löve, C. D. Moore, and G. Hensing, "Validation of the Swedish translation of the general self-efficacy scale," Quality of Life Research, journal article vol. 21, no. 7, September 01 2012, pp. 1249-1253.

[44] V. Braun and V. Clarke, "Using thematic analysis in psychology," Qualitative Research in Psychology, vol. 3, no. 2, 2006/01/01 2006, pp. 77-101.

[45] R. Landau, G. K. Ausland, S. Werner, N. Shoval, and J. Heinik, "Families' and professional caregivers' views of using advanced technology to track people with dementia," Qualitative Health Research, vol. 20, no. 3, 2010, pp. 409419.

[46] N. McNamara and J. Kirakowski, "Functionality, usability, and user experience: Three areas of concern," interactions, vol. 13, no. 6, 2006, pp. 26-28.

[47] J. E. Bono and G. McNamara, "Publishing in AMJpart 2: Research design," Academy of Management Journal, vol. 54 , no. 4, 2011, pp. 657-660.

[48] A. Anastasi and S. Urbina, Psychological testing, 7 ed. Upper Saddle River, NJ, US: Prentice Hall/Pearson Education, 1997. 